\title{
GPS SYSTEMS LITERATURE: INACCURACY FACTORS AND EFFECTIVE SOLUTIONS
}

\author{
Li Nyen Thin, Lau Ying Ting, Nor Adila Husna and Mohd Heikal Husin \\ School of Computer Sciences, Universiti Sains Malaysia, Malaysia
}

\begin{abstract}
Today, Global Positioning System (GPS) is widely used in almost every aspect of our daily life. Commonly, users utilize the technology to track the position of a vehicle or an object of interest. They also use it to safely navigate to the destination of their choice. As a result, there are countless number of GPS based tracking application that has been developed. But, a main recurring issue that exists among these applications are the inaccuracy of the tracking faced by users and this issue has become a rising concern. Most existing research have examined the effects that the inaccuracy of GPS have on users while others identified suitable methods to improve the accuracy of GPS based on one or two factors. The objective of this survey paper is to identify the common factors that affects the accuracy of GPS and identify an effective method which could mitigate or overcome most of those factors. As part of our research, we conducted a thorough examination of the existing factors for GPS inaccuracies. According to an initial survey that we have collected, most of the respondents has faced some form of GPS inaccuracy. Among the common issues faced are inaccurate object tracking and disconnection of GPS signal while using an application. As such, most of the respondents agree that it is necessary to improve the accuracy of GPS. This leads to another objective of this paper, which is to examine and evaluate existing methods as well as to identify the most effective method that could improve the accuracy of GPS.
\end{abstract}

\section{KEYWORDS}

GPS, accuracy factors, improve accuracy, global positioning system

\section{INTRODUCTION}

GPS plays an important role in position tracking and map navigation. Today, there are many GPS based application being developed, such as Waze, Google Maps, HERE maps and so on. Many people are concerned with the accuracy of GPS because the technology may not be accurate due to a number of reasons. Therefore, many researchers have tried to identify the factors that affect the accuracy of GPS $[1,2,3]$. Besides, they have also tried to identify the methods which can be used to improve it $[1,4,5,6,7,8,9]$. As a result, there are numerous approaches for different types of inaccuracy factors. In this paper, we examined the existing research on the factors that affect the accuracy of GPS based on the results we obtained from our initial survey. Most of the respondents who agreed that the inaccuracy of GPS is mainly caused by a weak GPS satellite signal. Besides that, some of them also assumes that the GPS receiver error and environment factors could also contribute to the issue. Based on the results, we identified existing research on the factors that affect the accuracy of GPS and examine the existing methods on improving the GPS signal accuracy. Based on research by Lin et al. [1], Iqbal et al. [2] as well as Bajaj, Ranaweera and Agrawal [3], we found that the factors that affect the GPS accuracy could be separated into 3 categories: 1) GPS satellite signal, 2) GPS receiver and, 3) the environment factor. As for the methods to improve the accuracy of GPS, there are three main methods suggested by different researchers. One of the method is making use of reference stations network to calculate the difference between the positions indicated by the systems of satellite and the

DOI : 10.5121/ijenc.2016.8211 
known fixed positions [4,5]. Besides that, Huang and Tsai [4] suggested the use of Perceptive GPS which applies Newton's Law to improve the overall accuracy of GPS. The third method was suggested by Lin et al. [1], Qi and Moore [7], Malleswari et al. [8] and White et al. [9], where the GPS accuracy could be improved via the use of software algorithms. We then compared the known factors that affect the GPS accuracy and the existing solutions in order to identify an effective solution for most of the factors. The comparison was done via a thorough examination of the published results while referring to the factors identified earlier.

Our paper is separated into the following sections: section two examines the related works for factors that affect GPS accuracies and the existing solutions suggested by other researchers. This is followed by an analysis by comparing the factors against the possible solutions to GPS inaccuracies. Next, we discussed the most likely solution for most of the factors, followed by our conclusion as well as future work for this research..

\section{RELATED WORK}

\subsection{Factors that Affect the GPS Accuracy}

Initially, in order to identify the factors that affect the accuracy of a GPS signal, we conducted an initial survey with a group of volunteers. The survey was initiated in order to identify the top issues that is faced by users of GPS applications. We managed to obtain 50 respondents that had varying levels of experience with such applications. From the results, 92\% of the respondents have used a GPS based applications before. Out of the $92 \%$ of respondents, $78.3 \%$ has faced inaccuracy of GPS when using the GPS based application. Besides that, $78.3 \%$ of the respondents agree that the inaccuracy of GPS is mainly caused by a weak GPS satellite signal. In addition, some of the respondents also agreed that the GPS receiver errors and environment factors plays a role in the increased inaccuracies of GPS. Based on the results we obtained from our survey, we identified related works about the factors that affect the accuracy of GPS from the existing research as shown in this section.

According to the related work found from the existing research, both the GPS receiver and the satellite signal transmission can affect the accuracy of GPS positioning. The accuracy of GPS depends on the signal strength of satellite signals and the receiving process of the receiver [1]. Before the year 2000, the most important factor in degradation of GPS signal error is caused by selective availability (SA) [2] as selective availability can cause less accurate positioning. The feature is permanently deactivated due to the broad distribution and worldwide use of the GPS system [2]. At the moment, there are different factors that can affect the accuracy of GPS. Table 1 highlights some of the major effects and errors rates that could occur with the GPS technology.

Table 1. Factors related to error rates.

\begin{tabular}{|l|l|}
\hline \multicolumn{1}{|c|}{ Effect } & \multicolumn{1}{c|}{ Error values } \\
\hline Ionospheric effects & \pm 5 meters \\
\hline Shifts in the satellite orbits & \pm 2.5 meters \\
\hline Clock errors of the satellites' clocks & \pm 2 meters \\
\hline Multipath effect & \pm 1 meter \\
\hline Tropospheric effects & \pm 0.5 meter \\
\hline Calculation and rounding errors & \pm 1 meter \\
\hline
\end{tabular}

From Table 1, it can be seen that ionospheric effect causes the most significant error in GPS accuracy. In the ionosphere at the height of $80-400 \mathrm{~km}$ a large number of electrons and positive charged ions are formed by the ionizing force of the sun. These layers refract the electromagnetic waves from the satellites which leads to an elongated runtime of the signals. Figure 1 shows the region of ionosphere and troposphere 


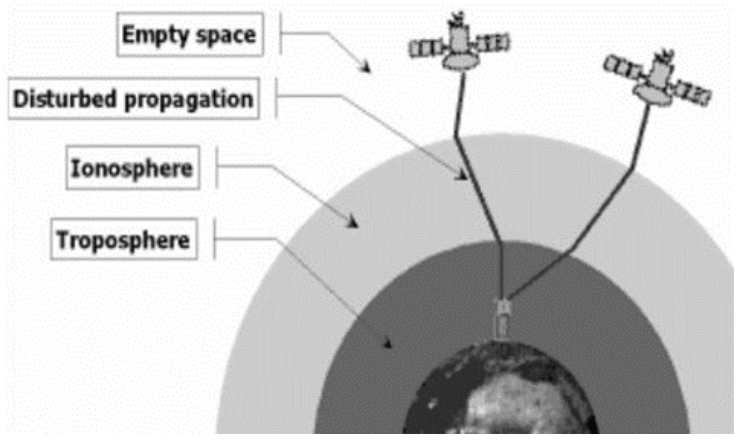

Figure 1. Ionosphere and Troposphere Regions

To sum up, the main factor that leads to GPS signal error can be classified into 3 aspects, namely GPS satellite signal, GPS receiver and usage environment as shown in Table 2 below.

Table 2. General factors that affect the accuracy of GPS positioning [2, 3].

\begin{tabular}{|l|l|l|}
\hline GPS satellite signal & GPS receiver & Usage environment \\
\hline Number of satellite visible [2] & $\begin{array}{l}\text { Receiver clock } \\
\text { errors }\end{array}$ & Ionosphere and troposphere delay \\
\hline Satellite geometry/shading [2] & - & Orbital errors \\
\hline Satellite position [3] & - & Ephemeris errors \\
\hline Signal delay [3] & - & Multi-path distortion \\
\hline Satellite clock errors [3] & - & Numerical errors \\
\hline
\end{tabular}

\subsection{Main Methods to Improve GPS Accuracy}

There are a number of existing methods to improve the accuracy of GPS. Table 3 highlights the most common methods implemented today.

Table 3. Methods to improve accuracy of GPS positioning

\begin{tabular}{|c|c|}
\hline Methods & Explanation \\
\hline $\begin{array}{l}\text { Reference Station } \\
\text { Networks }\end{array}$ & $\begin{array}{l}\text { A network of fixed ground based reference stations to compute } \\
\text { the difference between the positions indicated by the systems of } \\
\text { satellite and the known fixed positions [4]. These reference } \\
\text { stations broadcast the difference between the measured satellite } \\
\text { pseudoranges and actual pseudoranges to the GPS receiver to } \\
\text { improve its preciseness. If such difference is directly broadcast } \\
\text { from ground-based station to GPS receiver, it is called DGPS } \\
\text { (Differential GPS) [5]. WAAS (Wide Area Augmentation } \\
\text { System) [6] enhances this correction with satellites orbiting. }\end{array}$ \\
\hline Software algorithm & $\begin{array}{l}\text { E.g., Kalman Filter [7,8], map-matching algorithm [9], Google } \\
\text { Map GPS tracking algorithm [1] }\end{array}$ \\
\hline Perceptive GPS & $\begin{array}{l}\text { PGPS applies Newton's Law to model and calibrate the GPS } \\
\text { receiver's performance and it is made up of two phases: training } \\
\text { phase and rectification phase. Inside training phase, first step is } \\
\text { data collection, the received GPS raw information is inserted } \\
\text { into NMEA sentences [4]. Data of carrier's behaviour is then } \\
\text { obtained from resulted NMEA sentences [4]. Second step is } \\
\text { Noise Screening, it discovers noise and separate it out of the } \\
\text { original data [4]. Third step is Behaviour Learning, it adopt }\end{array}$ \\
\hline
\end{tabular}




\begin{tabular}{|l|l|}
\hline & $\begin{array}{l}\text { learning algorithm from HMM to perceive carrier's behaviour } \\
\text { [4]. Next, rectification phase is carried out. For first and second } \\
\text { step processes is similar as training phase. Third step is Motion } \\
\text { Awareness, transition matrix is used from training phase to be } \\
\text { aware of carrier's behaviour by classifying them into groups [4]. } \\
\text { Forth step is Data Rectification, it calibrates position data if } \\
\text { needed [4]. }\end{array}$ \\
\hline
\end{tabular}

\section{ANALYSIS}

In this section, the results about which existing improving methods can minimize the factors that affect the GPS accuracy are tabulated and analysed. These results are obtained from the research papers that we identified.

\subsection{Reference Station Networks}

Reference Station Networks was used by Wübbena to improve the accuracy of GPS [5]. According to Wübbena [5], the factors that can be reduced by utilizing this method are shown in the table below (Table 4).

Table 4. Factors that can be improved via the Reference Station Networks method [5]

\begin{tabular}{|c|c|}
\hline \multicolumn{2}{|c|}{ Reference Station Networks } \\
\hline Factor(s) that Affects GPS Accuracy & Result \\
\hline \multicolumn{2}{|l|}{ GPS Satellite Signal } \\
\hline $\begin{array}{l}\text { Number of Satellite Visible } \\
\text { Satellite Geometry/Shading } \\
\text { Satellite Position } \\
\text { Signal Delay } \\
\text { Satellite Clock Errors }\end{array}$ & $\begin{array}{l}\text { No } \\
\text { No } \\
\text { No } \\
\text { No } \\
\text { No }\end{array}$ \\
\hline \multicolumn{2}{|l|}{ GPS Receiver } \\
\hline Receiver Clock Errors & No \\
\hline \multicolumn{2}{|l|}{ Usage Environment } \\
\hline $\begin{array}{l}\text { Ionosphere and Troposphere Delay } \\
\text { Orbital Errors } \\
\text { Ephemeris Errors } \\
\text { Multi-Path Distortion } \\
\text { Numeric Errors }\end{array}$ & $\begin{array}{l}\text { Yes } \\
\text { Yes } \\
\text { No } \\
\text { No } \\
\text { No }\end{array}$ \\
\hline
\end{tabular}

Based on Table 4, the usage of Reference Station Networks can minimize ionosphere and troposphere delays as well as orbital errors. By minimizing these factors, the accuracy of GPS can be improved. 


\subsection{Kalman Filter Algorithm}

The Kalman Filter Algorithm was used by Qi [7] and Malleswari [8] to minimize some of the factors that affect the accuracy of GPS. Table 5 shows the common factors that affect the accuracy of GPS which can be minimized by this algorithm.

Table 5. Factors that can be improved via the Kalman Filter Algorithm method $[7,8]$

\begin{tabular}{|l|c|}
\hline \multicolumn{2}{|c|}{ Kalman Filter Algorithm } \\
\hline Factor(s) that Affects GPS Accuracy & Result \\
\hline \multicolumn{2}{|c|}{ GPS Satellite Signal } \\
\hline Number of Satellite Visible & No \\
Satellite Geometry/Shading & No \\
Satellite Position & No \\
Signal Delay & No \\
Satellite Clock Errors & Yes \\
\hline \multicolumn{2}{|c|}{ GPS Receiver } \\
\hline Receiver Clock Errors & Yes \\
\hline \multicolumn{2}{|c|}{ Usage Environment } \\
\hline Ionosphere and Troposphere Delay & Yes \\
Orbital Errors & No \\
Ephemeris Errors & Yo \\
Multi-Path Distortion & No \\
Numeric Errors
\end{tabular}

According to the table above, Kalman Filter Algorithm can minimize four factors that affect the accuracy of GPS, which are Satallite Clock Errors, Receiver Clock Errors, Ionosphere and Troposphere Delay and Multi-Path Distortion. By minimizing these four factors, the accuracy of GPS can be improved.

\subsection{Map-Matching Algorithm}

The Map-Matching Algorithm was used by Alain in [9]. This algorithm was used by Alain to improve the accuracy of user's location in a GPS based system. According to Alain [9], this algorithm is applied to the GPS based system so that the user's location which is not accurate can be reconciled with a map/network which is not accurate as well. Hence, the factors that affect the GPS accuracy cannot be minimized by using the algorithm as shown in Table 6 . 
International Journal of Computer Networks \& Communications (IJCNC) Vol.8, No.2, March 2016

Table 6. Factors that can be improved via the Map-Matching Algorithm method [9]

\begin{tabular}{|l|c|}
\hline \multicolumn{2}{|c|}{ Map-Matching Algorithm } \\
\hline Factor(s) that Affects GPS Accuracy & Result \\
\hline \multicolumn{2}{|c|}{ GPS Satellite Signal } \\
\hline Number of Satellite Visible & No \\
Satellite Geometry/Shading & No \\
Satellite Position & No \\
Signal Delay & No \\
Satellite Clock Errors & No \\
\hline \multicolumn{2}{|c|}{ GPS Receiver } \\
\hline Receiver Clock Errors & No \\
\hline \multicolumn{2}{|c|}{ Usage Environment } \\
\hline Ionosphere and Troposphere Delay & No \\
Orbital Errors & No \\
Ephemeris Errors & No \\
Multi-Path Distortion & No \\
Numeric Errors
\end{tabular}

\subsection{Perceptive GPS}

Perceptive GPS (PGPS) was used by Chung [4] is to improve GPS accuracy. According to Newton's Third Laws, This algorithm uses GPS data as navigation reference units to infer the motion of the carrier. The PGPS method does not require an auxiliary hardware to support it and it is also sensitive to the carrier's behaviour. The table below (Table 7) show the factors that affect the GPS positioning accuracy and the specific factors that cannot be mitigated by the method.

Table 7. Factors that can be improved via the Perceptive GPS [4]

\begin{tabular}{|l|c|}
\hline \multicolumn{2}{|c|}{ Perceptive GPS } \\
\hline Factor(s) that Affects GPS Accuracy & Result \\
\hline \multicolumn{2}{|c|}{ GPS Satellite Signal } \\
\hline Number of Satellite Visible \\
Satellite Geometry/Shading & Yes \\
Satellite Position & No \\
Signal Delay & Yes \\
Satellite Clock Errors & No \\
\hline \multicolumn{2}{|c|}{ GsS Receiver } \\
\hline Receiver Clock Errors & No \\
\hline \multicolumn{2}{|c|}{ Yes } \\
\hline Ionosphere and Troposphere Delay & No \\
Orbital Errors & No \\
Ephemeris Errors & No \\
Multi-Path Distortion & No \\
Numeric Errors & No \\
\hline
\end{tabular}


According to the Chung [4], this algorithm can minimize only three factors that affect the accuracy of GPS, which are Receiver Clock Errors, Number of Satellite visible, and Satellite Position which have been shown in the table above. Hence, the accuracy of GPS can be improved by minimizing these three factors.

\subsection{Google Map GPS Tracking Enhancement}

Lin used an algorithm to improve the accuracy of GPS tracking in the Google Map application [1]. This algorithm does not specifically minimize any factors that affect the accuracy of GPS but it improves the design for a location displayed on the map's application [1]. Table 8 highlights the effectiveness of the GPS Tracking Enhancement in terms of mitigating specific inaccuracy factors.

Table 8. Factors that can be improved via the Google Map GPS Tracking Enhancement method [1]

\begin{tabular}{|c|c|}
\hline \multicolumn{2}{|c|}{ Google Map GPS Tracking Enhancement } \\
\hline Factor(s) that Affects GPS Accuracy & Result \\
\hline \multicolumn{2}{|l|}{ GPS Satellite Signal } \\
\hline Number of Satellite Visible & No \\
\hline Satellite Geometry/Shading & No \\
\hline Satellite Position & No \\
\hline Signal Delay & No \\
\hline Satellite Clock Errors & No \\
\hline \multicolumn{2}{|l|}{ GPS Receiver } \\
\hline Receiver Clock Errors & No \\
\hline \multicolumn{2}{|l|}{ Usage Environment } \\
\hline Ionosphere and Troposphere Delay & No \\
\hline Orbital Errors & No \\
\hline Ephemeris Errors & No \\
\hline Multi-Path Distortion & No \\
\hline Numeric Errors & No \\
\hline
\end{tabular}

\section{RESUlt AND DisCuSSION}

According to results in Table 9, the Reference Stations Network proposed by Wübbena [5] to improve the accuracy of GPS can reduce only two factors that affect the accuracy of GPS. For the Kalman Filter Algorithm which was used by Qi [7] and Malleswari [8], manged to mitigate four factors that affect the accuracy of GPS whereas for PGPS which used by Chung [4], only three GPA inaccuracy factors can be rectified. Map-Matching Algorithm which was applied by Alain [9] and the Google Map GPS Tracking Enhancement explored by Lin [1] does not have any impact on the listed factors that affect the accuracy of GPS. However, both of these methods could improve the GPS tracking activities in other ways such as effective interface on map applications. Hence, the most effective method which can improve the accuracy of GPS is the Kalman Filter Algorithm used by Qi [7] and Malleswari [8]. PGPS [4] and Reference Stations Network [5] can be suggested as alternative methods to improve the GPS accuracy as well. According to Malleswari [8], the Kalman Filter Algorithm is a linear recursive filtering method which can be applied to smoothen the location coordinates data obtained by the GPS receiver. Besides that, when the location coordinates of the GPS user is being estimated, this algorithm can boost the accuracy of GPS by reducing the estimation error to the lowest value. 
Table 9. Overall existing methods and the inaccuracy factors that could be mitigated

\begin{tabular}{|c|c|c|}
\hline & $\begin{array}{l}\text { Methods to Improve the } \\
\text { Accuracy of GPS }\end{array}$ & Specific factors mitigated via the methods \\
\hline 1 & $\begin{array}{l}\text { Reference Stations Network } \\
{[5]}\end{array}$ & Ionosphere and Troposphere Delay, Orbital Errors \\
\hline 2 & $\begin{array}{l}\text { Kalman Filter Algorithm } \\
{[7,8]}\end{array}$ & $\begin{array}{l}\text { Satellite Clock Errors, Receiver Clock Errors, } \\
\text { Ionosphere and Troposphere Delay, } \\
\text { Multi-Path Distortion }\end{array}$ \\
\hline 3 & Map-Matching Algorithm [9] & None \\
\hline 4 & Perceptive GPS (PGPS) [4] & $\begin{array}{l}\text { Number of Satellite Visible, Satellite Position, Receiver } \\
\text { Clock Errors }\end{array}$ \\
\hline 5 & $\begin{array}{l}\text { Google Map GPS Tracking } \\
\text { Enhancement [1] }\end{array}$ & None \\
\hline
\end{tabular}

\section{CONCLUSION}

As a conclusion, GPS technology is very important to everyone because it helps users in different daily life activities such as map navigation, product tracking and more. Hence, the inaccuracy of GPS faced by many users must be reduced so that they will not any issues while tracking or navigating with a GPS-enabled devices. In this paper, we discussed about the factors that affect the accuracy of the GPS and the existing methods that can mitigate issues or improved the overall usability of the technology. After examining and evaluating all of the existing improvement methods, we found that the most effective method to improve the accuracy of GPS is the Kalman Filter Algorithm because it is able to resolve up to four factors that affect the accuracy of GPS. Hence, if a researcher wishes to improve the accuracy of GPS, the Kalman Filter Algorithm would be most suited to mitigate specific factors that affects the technology's accuracy when compared to other existing methods.

As part of the future research, we aim to utilize the Kalman Filter Algorithm in a number of simulations that mimics the inaccuracy factors. These simulations may allow us to identify enhancements that could be applied to the algorithm and mitigate the other seven factors as well.

\section{REFERENCES}

[1] Lin, J.Y, Yang, B.K., Tuan A.D., and Chen, H.C. (2013). "The Accuracy Enhancement of GPS Track in Google Map", 2013 Eighth International Conference on Broadband and Wireless Computing, Communication and Applications, Compiegne, France. pp. 524-527.

[2] Iqbal, A., Mahmood. H., Farooq, U., Kabir, M.A. and Asad, M.U.. (2009). "An Overview of the Factors Responsible for GPS Signal Error: Origin and Solution”, 2009 International Conference on Wireless Networks and Information Systems, Shanghai, China. pp. 294-299.

[3] Bajaj, R., Ranaweera, S.L., Agrawal, D.P.. (2002). "GPS: Location-tracking Technology", Computer, vol.35, no..4, pp. 92-94.

[4] Huang, J.Y., and Tsai, C.H.. (2008). "Improve GPS Positioning Accuracy with Context Awareness", 2008 First IEEE International Conference on Ubi-Media Computing, Lanzhou, China, pp. 94-99.

[5] Wubbena, G., Andreas, B., Seeber, G., Boder, V. and Hankemeier, P., (1996). "Reducing Distance Dependant Errors for Real-Time Precise DGPS Applications by Establishing Reference Station Networks". In Proceedings of the 9th International Technical Meeting of the Satellite Division of the Institute of Navigation (ION GPS-96) 
International Journal of Computer Networks \& Communications (IJCNC) Vol.8, No.2, March 2016

[6] Enge, P., Walter, T., Pullen, S., Kee, C., Chao, Y. and Tsai, Y. (1996). "Wide area augmentation of the global positioning system". Proceedings of the IEEE, vol. 84 Aug. 1996, pp. 1063-1088.

[7] Qi, H. and Moore, J. B. (2002). "Direct Kalman Filtering Approach for GPS/INS Integration”, IEEE Trans. Aerosp, Electron. System. vol. 38, no. 2, 2002, pp. 687-693.

[8] Malleswari, B.L., MuraliKrishna, I.V., Lalkishore, K., Seetha, M., Nagaratna, P. H. "The Role of Kalman Filter in the Modelling of GPS Errors", Journal of Theoretical and Applied Information Technology, pp. 95-101.

[9] White, C.E., Bernstein, D. and Kornhauser, Alain L.. (2000). "Some map matching algorithms for personal navigation assistants”. Transportation Research Part C, No. 8, 2000, pp. 91-108. 